\title{
ARISTÓTELES Y EL PENSAMIENTO POLÍTICO ARISTOCRÁTICO*
}

\author{
Manuel Knoll \\ Istanbul Şehir University
}

\begin{abstract}
RESUMEN / ABSTRACT
Según una influyente línea interpretativa, la mejor polis de Aristóteles debe ser considerada una politeia $(\pi \mathrm{o} \lambda \imath \varepsilon \varepsilon i ́ \alpha)$. Esta corriente predomina aún hoy entre los eruditos alemanes. En tanto paladina de la "social democracia aristotélica", Martha Nussbaum pertenece también a esta línea exegética. En oposición a tales interpretaciones, este ensayo defiende la tesis de que Aristóteles pertenece a la tradición de pensamiento político aristocrático. Esta tradición se remonta a Teognis, Heráclito y Platón y se inicia como una crítica dirigida tanto a la decadencia de la virtud aristocrática cuanto al ascenso de valores democráticos e igualitarios.

Este trabajo demuestra que Aristóteles concibe las diferentes formas de constitución como manifestaciones de distintas concepciones de la justicia distributiva. Aristóteles mantiene una clara preferencia por una concepción aristocrática de la justicia, y, por tanto, por la aristocracia. La constitución de la mejor polis que detalla en los libros VII y VIII de la Política debe entenderse como una "verdadera aristocracia" en la que los cargos políticos son distribuidos según el mérito ( $\kappa \alpha \tau^{\prime}$ à $\left.\xi \dot{\alpha} \alpha v\right)$ entre los ciudadanos que sean los mejores desde el punto de vista moral e intelectual.
\end{abstract}

Palabras Clave: Aristóteles, pensamiento político aristocrático, justicia distributiva, aristocracia, mejor polis.

\section{ARISTOTLE AND ARISTOCRATIC POLITICAL THOUGHT}

According to an influential line of scholarship, Aristotle's best city has to be interpreted as a politeia ( $\pi 0 \lambda \imath \tau \varepsilon i \alpha)$. This line of thought is still dominant among German scholars. As a champion of "Aristotelian Social Democracy", Martha Nussbaum is part of this line as well. Against such interpretations, this paper substantiates the thesis that Aristotle belongs in the tradition of aristocratic political thought. That tradition goes back to Theognis, Heraclitus, and Plato. It started with a critique of both the decline of aristocratic virtues and the rise of democratic and egalitarian values.

This paper demonstrates that Aristotle understands the different forms of constitution as embodiments of different conceptions of distributive justice. It shows that Aristotle has a clear preference for the aristocratic conception and, as a consequence, for aristocracy. The constitution of the best city, which he outlines in Books VII and VIII of the Politics, has to be understood as a "true aristocracy" in which the political offices are distributed according to worth ( $\left.\kappa \alpha \tau^{\prime} \dot{\alpha} \xi i \alpha v\right)$ to the morally and intellectually best citizens.

KEYWORDS: Aristotle, aristocratic political thought, distributive justice, aristocracy, best city.

Este trabajo se ha realizado en el marco del proyecto FFI2016-76547-P de la Subdirección FFI2016-76547-P de Investigación del Ministerio de Economía e Innovación del Reino de España. 
$\overline{R M}$ En la Grecia clásica hay una importante corriente de pensamiento político aristocrático que se remonta a Heráclito y Teognis, ambos de estirpe noble

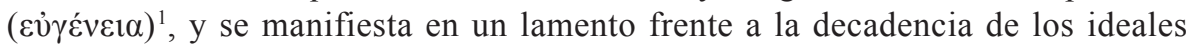
aristocráticos y la creciente hegemonía de la democracia y el igualitarismo. Heráclito rechaza el ofrecimiento del pueblo de Éfeso para que ejerza la función de legislador, indicando que "la ciudad se rige por una mala constitución ( $\pi$ o $\lambda ı \varepsilon \varepsilon i ́ \alpha)$ )" (Diógenes Laercio, IX, 2) y enfatizando la desigualdad entre los seres humanos: "Pienso que un

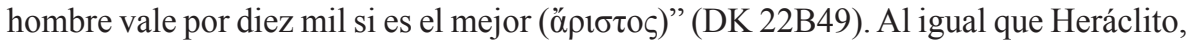
Teognis aborrece la eclosión de la masa popular en Megara tras la acumulación de riqueza y la apertura de un proceso democrático. Asimismo, critica la revalorización de los valores aristocráticos y que el dinero se haya vuelto más importante que una disposición aristocrática. Como todos los pensadores políticos aristocráticos, piensa que

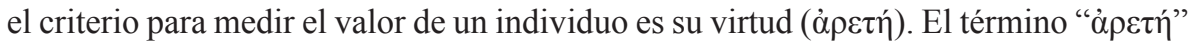
significa también "excelencia” o "estado óptimo". Teognis está convencido, de nuevo en línea con los pensadores políticos aristocráticos, de que, no la muchedumbre, sino solo un número reducido de hombres puede alcanzar la virtud (Theognidea, I, 150,

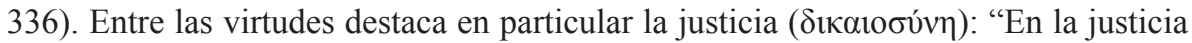

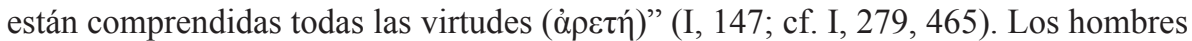

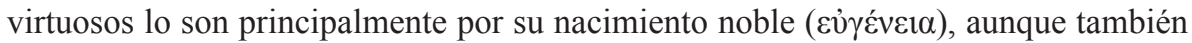

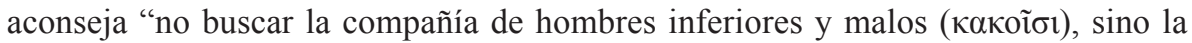
de gente decente ( $\dot{\alpha} \gamma \alpha \theta \tilde{\omega} v)$. Júntate con ellos, comparte con ellos, y complace a los poderosos. De los nobles ( $\dot{\varepsilon} \sigma \theta \lambda \tilde{\omega} v)$ aprenderás cosas elevadas, pero si te relacionas con el vulgo, perderás tu buen sentido" (I, 30-36). Los buenos se corrompen debido a los malos, por tanto uno debería mezclarse con gente semejante. Admite la posibilidad de que un padre decente engendre un hijo malo ( $\mathrm{I}, 436)$, pero los malos nacen malos y lo seguirán siendo durante toda su vida. Admite también que no nacen enteramente malos sino que aprenden su mala conducta por su asociación con gente mala (I, 305-308). Y niega que pueda enseñárseles la virtud: "la gente mala no deviene buena por medio de la educación" (I, 437-38).

El representante más renombrado de la tradición de pensamiento aristocrático es Platón, descendiente de una de las más rancias familias nobles en Atenas. Platón conoce la obra de Teognis del que cita versos en sus diálogos (Leyes I, 630a-c; Menón 95d-96a). Contrariamente a Teognis, estima que la virtud de las personas no se funda

Agradezco a Renato Cristi su traducción de este trabajo e inspiradoras discusiones en torno a Teognis y la tradición aristocrática del pensamiento político.

1 Con respecto a Pitágoras y sus discípulos, Diógenes Laercio informa acerca del tipo de gobierno que propició su Escuela. "Siendo aproximadamente trescientos en número, gobernaron tan bien la ciudad que su constitución fue efectivamente una verdadera aristocracia (gobiernos de los mejores)" (VIII, 3). 


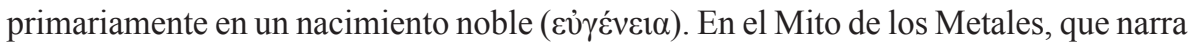
en la República, defiende la posibilidad de que un hijo de campesinos o artesanos pueda adquirir la virtud y ser elevado así a la casta de los guardianes (Rep. III, 415c). Esta postura posiblemente derive de su amistad con Sócrates, un hombre de gran virtud e hijo de un escultor y una partera. Por ello, Platón dedica tanto espacio al tema de la educación. En el Protágoras, luego de refutar la tesis que la virtud puede ser enseñada, Sócrates se retracta hacia el final del diálogo (319a, 328c, 361a/b) al sostener que las virtudes pueden ser enseñadas porque son una forma de conocimiento que dirige nuestra conducta (Protágoras 361a/b; Menón 87c). Por tanto, Platón es un pensador aristocrático en el sentido más literal del término, a saber como partidario del gobierno de los mejores y más virtuosos. En la República, no solo elabora un perfil de la mejor ciudad sino también de los mejores individuos que la deben gobernar. Para la constitución de la mejor ciudad, Platón la identifica mediante dos nombres: "Si entre los que gobiernan un individuo sobresale, se llama monarquía ( $\beta \alpha \sigma 1 \lambda \varepsilon i \alpha)$; si gobierna

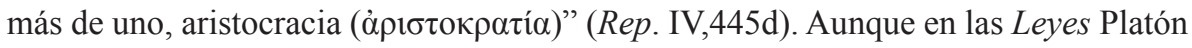
estipula la necesidad de un Estado de derecho, asegura que son los individuos mejores y más virtuosos quienes gobiernan en el régimen que diseña ${ }^{2}$.

Este trabajo postula que no solo Platón sino también Aristóteles pertenecen a la tradición griega del pensamiento político aristocrático ${ }^{3}$. En la literatura, la cuestión de las opciones políticas de Aristóteles es un tema controvertido. Su conocido esquema de seis constituciones no incluye un criterio que permita responder a la pregunta acerca de cuál de las tres constituciones correctas es aquella por la que opta. En la

Knoll 2009b, 35-48; cf. Schöpsdau 1994, 123; Sternberger 1984, 135.

Entre los filósofos modernos, Nietzsche es quien más claramente puede ser adscrito a la tradición del pensamiento político aristocrático. En 1887, Georg Brandes, un intelectual danés, describe la postura de Nietzsche como un "radicalismo aristocrático". Nietzsche mismo aprueba esta designación en su respuesta a la carta de Brandes señalando "que le parecía la observación más clarividente acerca de sí mismo hasta la fecha" (Middleton 1996, 279). Al igual que sus precursores en Grecia clásica, Nietzsche es un convencido de que la gente es fundamentalmente desigual y de un valor desigual. Su filosofía mantiene un compromiso con la virtud y la excelencia humana (cf. Brobjer 1995). La finalidad principal de la sociedad y la política es la creación de tipos humanos superiores que pueden mejor exhibir esas características (Appel 1999, 2, 13; Detwiler 1990,189; Knoll 2009a). En una investigación reciente, Renato Cristi ha demostrado por primera vez el papel significativo que tiene Teognis en la formación temprana del pensamiento aristocrático de Nietzsche (Cristi 2014, Nietzsche 2015). El radicalismo aristocrático de Nietzsche está determinado por todos los antiguos precursores de esta tradición. De Heráclito, a quien concibe como una alma gemela, obtiene su concepción heroica de la filosofía como una lucha por las ideas y el pensamiento. Platón claramente determina su concepción aristocrática de la justicia distributiva y su visión de un orden social justo (Knoll 2009a). Al igual que estos pensadores de la Antigüedad, Nietzsche se opone a los valores democráticos e igualitarios prevalentes en esa época. Al igual que Teognis intenta la re-evaluación de los valores en una dirección aristocrática que reconozca la jerarquía y el rango social. 
monarquía, la aristocracia y la politeia $(\pi \mathrm{o} \lambda \tau \tau \varepsilon i ́ \alpha)^{4}$, quienes gobiernan lo hacen con vistas al bien común ( En la descripción de la mejor polis que presenta en los libros VII y VIII de su Política, Aristóteles no la nombra. Hay dos importantes razones por las que hasta hoy no hay acuerdo acerca de cuáles serían sus convicciones políticas fundamentales. La primera corriente interpretativa, que prevalece entre los estudiosos de la tradición anglosajona, es que su mejor polis es una aristocracia de los mejores (Barker 1959, 353; Keyt 1991, 260; Mulgan 1991, 318; Depew 1991, 346, 362; Chuska 2000, 322-23; Bates 2003, 97). La segunda, todavía dominante entre los intérpretes germanos, entiende la mejor constitución aristotélica como un gobierno mixto que él denomina "politeia" (Bien 1980, 315 ss.; Ottmann 2001, 210; Sternberger 1984, 119, 127, 156). Como defensora de una "democracia social aristotélica", Martha Nussbaum pertenece también a esta última corriente (1990a; 2000, 109; 2001, 147).

En este trabajo examino las preferencias políticas de Aristóteles y defiendo la tesis de que es necesario situarlo en la tradición del pensamiento aristocrático. Presto atención a su teoría de la justicia distributiva y concluyo que Aristóteles favorece una concepción aristocrática de la justicia distributiva. La constitución de la mejor polis que presenta en los libros VII y VIII de la Política, corresponde a una constitución aristocrática. La justicia es la noción más relevante en su filosofía política. En este sentido, en su Ética a Nicómaco cita a Teognis cuando éste afirma que "en la justicia están comprendidas todas las excelencias" (ENV, 1, 1129b 29; cf. Theognidea, I, 147). Aristóteles también se refiere y se muestra de acuerdo con la opinión de Teognis en el sentido de que la virtud no puede enseñarse (Theognidea, I, 437-38; EN X, 9, 1179b 4-7). Según Aristóteles, los argumentos teóricos (oi $\lambda o ́ \gamma o t$ ) no sirven para que la multitud adquiera nobleza moral. Pero pueden servir para "alentar y estimular a jóvenes generosos y para que un

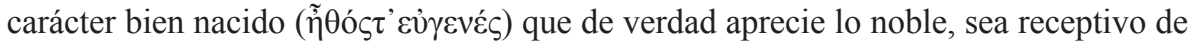

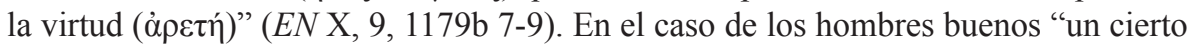
entrenamiento en la virtud se logra por la compañía de gente decente, como afirma Teognis" (EN IX, 9, 1170a11-13; cf. Theognidea, I, 35; cf. EN IX, 12, 1172a13-14).

Estudiar la filosofía política de Aristóteles implica enfrentar un problema filológico muy importante, ¿debe considerarse la Política como una obra unificada, o

4 Aristóteles observa a propósito de esta constitución que "cuando la multitud gobierna apuntando al bien común, se conoce por el término común a todos los regímenes, a saber politeia” (Pol. III, 7, 1279a 38-39). Según Günther Bien, la elección del término genérico "politeia" para designar esta constitución específica muestra que Aristóteles la prefiere y que para él la teoría política es primariamente una teoría de esta particular constitución (Bien 1980, 316, 319-20). Este argumento no es convincente. Aristóteles no elige el término "politeia" sino que lo toma del uso común (cf. Pol. II, 6, 1265b28-29). En la Ética a Nicómaco observa que el nombre "politeia" es, en sentido estricto, inapropiado para este tipo de constitución. "Las constituciones son la monarquía, la aristocracia, y en tercer lugar la basada en la tenencia de propiedad, a la que parece correcto llamar "timocracia", aunque la mayoría de la gente la llama "politeia" (EN VIII, 10, 1160a32-35). 
debe entendérsela como dos tratados escritos en momentos diferentes, o alternativamente como una colección de ensayos políticos escritos en diferentes épocas? ${ }^{5}$. Este trabajo se funda en una tesis unitaria moderada, según la cual los ocho libros de la Política desarrollan una teoría unificada y coherente de las constituciones ${ }^{6}$.

\section{La teoría aristotélica de las constituciones}

Aristóteles expone su teoría de las constituciones en los libros II-VII. Para un pensador político clásico, el término "constitución ( $\pi \mathrm{o} \lambda \iota \tau \varepsilon i ́ \alpha)$ " tiene un significado distinto del que tiene actualmente. En el libro III, Aristóteles presenta su doctrina de las seis constituciones y ensaya su primera definición del término:

Una constitución es el orden de una polis y de sus distintas magistraturas, en particular de su magistratura suprema. La magistratura suprema es, en todas partes, el gobierno de la polis; de hecho, el gobierno es la constitución misma (Pol. III,6,1278b8-11) .

Aristóteles entiende la constitución como un orden ( $\tau \alpha \dot{\xi} \xi 1 \zeta)$ que determina quién gobierna en una comunidad política. También identifica la constitución con el grupo de ciudadanos que gobierna. Fundado en el significado literal de término, define la democracia como el gobierno del pueblo $(\delta \tilde{\eta} \mu \mathrm{s})$, y la oligarquía como el gobierno de unos pocos (ỏ $\lambda$ í $\gamma o t)$ (Pol. III, 6, 1278b11-13). De acuerdo con este criterio, introduce su esquema de seis constituciones, que distingue entre tres constituciones justas (monarquía, aristocracia y politeia), y tres corruptas (tiranía, oligarquía y democracia).

El esquema constitucional de Aristóteles deriva de Platón, tal como lo desarrolla en el Político. En este diálogo, el huésped de Elea divide las constituciones en tres justas y tres corruptas, taxonomía fundada en un criterio cuantitativo: el gobierno de uno, de pocos o de la multitud. Aunque coinciden en el uso de las denominaciones monarquía/ tiranía y aristocracia/oligarquía, difieren, pues Platón usa el término 'democracia' para referirse a la forma justa y la forma corrupta del gobierno de todos (Político 302c/d; Pol. III, 7, 1279a32-1279b10). Otras dos diferencias consisten en que Platón postula una paradigmática séptima constitución, en la que uno o unos pocos poseedores de conocimiento gobiernan con sabiduría (Político 293e, 297b/c, 302c-303b) y distingue las tres constituciones justas de las corruptas según que los que gobiernan lo hagan conforme

5 Para un bosquejo de la controversia entre la interpretación genético-analítica de la Política y la interpretación unitaria, ver Schütrumpf 1980, 287-326; Rowe 1991.

6 De acuerdo a la tesis unitaria robusta, los ocho libros de la Política deben ser considerados como un trabajo coherente y unitario. Aunque hay muchas razones y argumentos que recomiendan esta tesis, nuestras fuentes no ofrecen evidencia irrefutable de ella. Para mis argumentos relativos a las dos versiones de la tesis unitaria, ver Knoll 2009b, 2011a, 2011b. Las traducciones de la Política siguen la edición de W.D. Ross (Aristóteles 1957). 
a derecho o no (Político 302d/e). Aristóteles distingue seis formas de constitución según

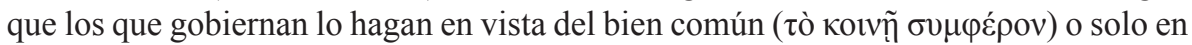
vista de su propia ventaja personal (Pol. III, 7, 1279a17-1279b10). En lo relativo a las tres constituciones corruptas, Aristóteles menciona la protección y la expansión de la riqueza $(\pi \lambda \circ \tilde{\text { vo }} \varsigma$ ) como el objetivo principal de la oligarquía y la tiranía, y la libertad

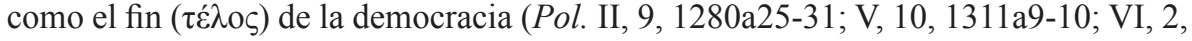
1317a40-b17; cf. EN VIII, 12, 1160b12-15).

El criterio que emplea Aristóteles en su taxonomía no es puramente cuantitativo (gobierno de uno, muchos, todos), ni puramente normativo-teleológico (el bien común). Destaca también la cualidad específica de quien gobierna o del grupo gobernante. Define así la democracia como el gobierno de los pobres, la oligarquía como el gobierno de los ricos, y la aristocracia, como el de los virtuosos. Por la combinación de estos tres aspectos se puede definir la democracia como el gobierno de muchos pobres para su beneficio propio; la oligarquía como el de pocos ricos para su propio beneficio; y la aristocracia como el de unos pocos virtuosos para el bien común (Pol. III, 7/8, 1279a321279b19). En sus tratados sobre la ética, Aristóteles identifica el bien común con la vida buena ( $\varepsilon \tilde{\zeta} \zeta \tilde{\eta} v)$ y la felicidad que concibe con el fin natural de la polis.

\section{Aristóteles y su teoría de la justicia distributiva}

En el libro V de la Ética a Nicómaco, Aristóteles desarrolla una teoría comprehensiva de

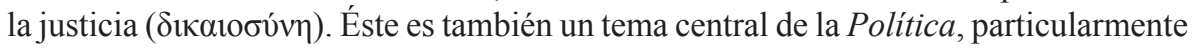
con respecto a la justicia distributiva, que Aristóteles discute en el libro III en el sentido

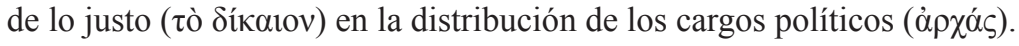

En el libro V de la Ética a Nicómaco, distingue entre justicia universal que requiere obedecer las leyes de la polis, y la justicia particular. A continuación, divide la justicia particular en justicia distributiva y conmutativa. Describe la primera como aquella que "se refiere a la distribución de honores, de dinero, o de otros recursos divisible entre quienes pertenecen a un comunidad" (EN V, 5, 1130b31-33 ${ }^{8}$. Aunque Aristóteles menciona al dinero y "otros recursos" como sujeto de justicia distributiva, esta forma de justicia se refiere primariamente a la justa distribución de cargos públicos

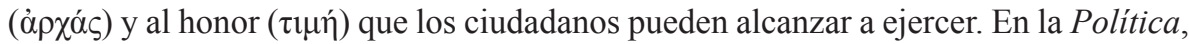
Aristóteles también declara: "las magistraturas son honores" (Pol. III, 10, 1281a31). En la Ética a Nicómaco se hace evidente que Aristóteles piensa que la justicia distributiva se relaciona primordialmente con la distribución del poder político. En ella, formula los dos principios formales de la justicia distributiva y examina la disputa política sobre los modos de darle contenido: Bywater (Aristóteles 1954). 
Lo justo involucra necesariamente al menos cuatro términos: dos personas para quienes algo es justo y las cosas en que se manifiesta. Existe la misma igualdad que se da entre las cosas y las personas, porque las cosas tienen la razón entre sí que tienen las personas entre ellas: si las personas no son iguales, no obtendrán las mismas cosas. De aquí se originan las disputas y los reclamos, como cuando a personas iguales se les asignan o reciben porciones desiguales; o a desiguales iguales porciones. Esto también sucede en asignaciones por razón del valor. Todos están de acuerdo en que lo que es justo distributivamente debe serlo, en cierto sentido, de acuerdo con su valor. Pero no todos quieren significar el mismo tipo de valor: para los demócratas se trata de la libertad, para los partidarios de la oligarquía será la riqueza, para otros un noble abolengo, y para los aristócratas lo será la virtud. De este modo la justicia es una suerte de proporcionalidad ( $E N$ V, 6, 1131a18-29).

La justicia distributiva, a pesar de ser una especie de justicia, no es ciega; asigna los beneficios de la polis discriminando entre las personas y sus cualidades. Diferentes individuos tienen diferentes cualidades y, en este sentido, se les asigna diferentes porciones. En una distribución justa, todas las personas deben recibir sus asignaciones en proporción a su valor o mérito ( $\alpha \xi i ́ \alpha)$ desigual. Aristóteles denomina esta forma de desigualdad igualdad "proporcional" o "geométrica", para distinguirla de la igualdad "numérica" o "aritmética" (ENV, 6, 1131a29ss. $)$. Una distribución ciudadana es justa si los bienes públicos asignados lo han sido de acuerdo a una igualdad proporcional o geométrica.

El pasaje de la Ética a Nicómaco contiene dos principios formales de la justicia distributiva. El primero establece que una distribución justa es la que opera según el mérito $\left(\kappa \alpha \tau^{\prime} \alpha^{\prime} \xi^{\prime} \alpha \nu\right)$. El segundo determina que porciones iguales deberían asignarse solo a personas iguales, mientras que personas desiguales deberían recibir porciones desiguales. La fórmula del primer principio debería ser: "a cada cual en proporción a su rango o mérito"; y la del segundo: "iguales porciones para iguales, desiguales para desiguales".

Aristóteles observa que existe consenso en que la justicia distributiva "debe ser según el valor o mérito en algún sentido", pero desacuerdo sobre el criterio o estándar apropiado para medir el mérito que está determinado por las convicciones políticas de los ciudadanos. Menciona cuatro grupos sociales que tienen convicciones políticas diversas y que implican cuatro diferentes criterios de valor. Los demócratas favorecen la

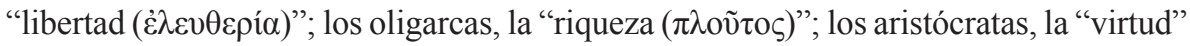

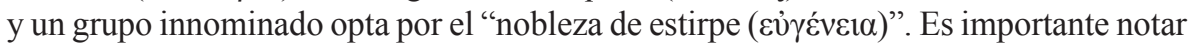
que para Aristóteles los verdaderos aristócratas son quienes sostienen que la virtud es el criterio de valor apropiado y el abolengo. De esta manera, Aristóteles encuentra cuatro maneras de dar contenido concreto a los dos principios formales de la justicia

$9 \quad$ En las Leyes, Platón desarrolla los elementos principales de la teoría de la justicia distributiva tal como la entiende Aristóteles (VI,757a-e). 
distributiva y puede distinguir entre cuatro concepciones: la democrática, la oligárquica, la aristocrática y una cuarta innominada ${ }^{10}$.

Aristóteles, en la Política, se refiere en dos oportunidades a la breve exposición acerca de la justicia distributiva que desarrolla en la Ética a Nicómaco (Pol. III, 9, 1280a16-25; Pol. III, 12, 1282b18-23). Es significativo que ambas referencias ocurran en el libro III que muchos consideran con razón que es el eje central de la Política ${ }^{11}$. Aristóteles acepta la idea de que las disputas en torno a la distribución de cargos políticos, la libertad, la riqueza, la estirpe y la virtud se justifican como criterios de valor apropiados. Sin embargo, ninguno de estos criterios tiene una "justificación absoluta" (Pol. III, 13, 1283a29-31). Los que defienden la concepción oligárquica de la justicia distributiva argumentan que los ricos pagan más impuestos, que son "por lo general más confiables en el cumplimiento de los contratos", y "son dueños de una mayor parte de la tierra", lo cual significa "un beneficio público" (Pol. III, 9, 1280a25-31; Pol. III, 13, 1283a31-33). Por eso, piensan que estas razones justifican que los ricos posean una porción desigual del poder político. Aristóteles los critica porque no es posible derivar de una particular desigualdad de fortuna una desigualdad general que justifique una constitución oligárquica. Ese argumento sería convincente si la finalidad de la polis fuese la riqueza, pero para Aristóteles la riqueza y la prosperidad no son el verdadero objetivo de una comunidad política (Pol. III, 9, 1280a22-31; V, 1, 1301a31-36).

Los que adhieren a la concepción democrática de la justicia distributiva argumentan que todos los ciudadanos son iguales, porque todos nacieron libres. Por ello es justo que tanto pobres como ricos tengan una igual porción del poder político, lo que justifica que la democracia sea la constitución apropiada. Aristóteles también critica esta postura pues, afirma, no puede concluirse que de una igualdad particular en la libertad pueda justificarse una igualdad universal que valide una constitución democrática (Pol. III, 9, 1280a22-31; V, 1, 1301a28-36). Para Aristóteles, la libertad no puede considerarse como la verdadera finalidad de la polis.

En oposición a los partidarios de las concepciones democráticas y oligárquicas de la justicia distributiva, los que pertenecen a buenas familias argumentan en favor de su noble estirpe ( $\varepsilon \dot{\gamma} \gamma \varepsilon \dot{v} \varepsilon 1 \alpha$ ). Afirman que son ciudadanos con mayor mérito que aquellos de innoble nacimiento, que la estirpe célebre se considera un honor en toda comunidad, y que quienes descienden de padres nobles son probablemente mejores que los hijos de familias vulgares puesto que un nacimiento patricio es la virtud de la familia. Éste es el argumento que los bien nacidos usan para justificar una mayor participación del

10 Si aplicamos la distinción que introduce Rawls en A Theory of Justice. David Keyt explica que "podemos distinguir el concepto de justicia distributiva de sus varias concepciones". Keyt concibe esas diferentes concepciones como interpretaciones de un mismo principio de justicia distributiva (Keyt 1991, 242-43).

11 David Keyt considera que el libro III es el "núcleo en torno al cual gira todo el tratado" (Keyt 1991, 247). William L. Newman interpreta el libro III como "el centro de todo el tratado" (Newman 1887-1902, Vol II, XXXI). Las referencias internas del tratado muestran que esto es así (cf. Keyt/Miller 1991, 4). 
poder político (Pol. III, 13, 1283a33-37). Aristóteles, que define el nacimiento noble

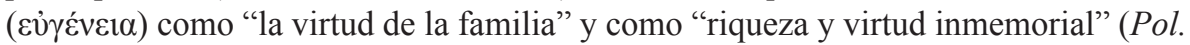
III, 13, 1283a37; IV, 8, 1294a21-22), critica la idea de las nobleza griega de su tiempo de que "de padres virtuosos nacen hijos virtuosos". Postula que "aunque la naturaleza pueda intentar alcanzar este objetivo no siempre es capaz de conseguirlo" (Pol. I, 6, 1255b3-5; cf. Theognis: Theognidea, I, 436).

III. Los argumentos de Aristóteles en favor de una concepción aristocrática de justicia y en favor de la aristocracia

La reconstrucción de los argumentos relativos a los de noble estirpe, los demócratas y los partidarios de la oligarquía muestra que cada concepción de la justicia distributiva está asociada a la constitución correspondiente. Por ejemplo, abogar por una distribución de cargos políticos según la riqueza es lo mismo que abogar por la oligarquía. Así, el debate político acerca de la justa distribución de los cargos y del criterio propio del valor equivale a una disputa sobre la constitución apropiada para la polis.

En el libro V de la Política, Aristóteles examina el cambio ( $\mu \varepsilon \tau \alpha \beta \mathrm{o} \lambda \eta \dot{)})$ de constitución y, en particular, por qué podría decaer y cómo preservarla. El capítulo 1 establece que la democracia y la oligarquía son las constituciones predominantes de su época. Es con respecto a estas dos constituciones que Aristóteles explica las causas generales y los motivos de sediciones y revoluciones. Su explicación se funda en su teoría de la justicia distributiva. Sostiene que la democracia y la oligarquía se originan a partir de las concepciones opuestas de ella que defienden sus partidarios (Pol. V, I, 1301a25-32). De estas concepciones derivan también sus juicios irreconciliables de la justicia de una distribución igual o desigual del poder político. Este desacuerdo es la razón de por qué las democracias y las oligarquías no son siempre constituciones estables. Los ciudadanos ricos buscan derrocar a las democracias porque sostienen que una distribución igualitaria del poder político es injusta. En la oligarquía, la sedición tiene su punto de partida en ciudadanos pobres que estiman que su exclusión de la vida política es injusta en su origen y así exigen igual participación en el gobierno de la polis (Pol. V, I, 1301a32-1202a13) $)^{12}$.

Aristóteles entiende las diferentes constituciones como manifestaciones de las diferentes concepciones de la justicia distributiva ${ }^{13}$. En la Política, explica el importante rasgo de la justicia que la capacita para mantener la comunidad política integrada. Una constitución no es solo el orden que determina cómo asignar el poder político en una polis, sino que también justifica éticamente esa asignación por medio de una concepción de justicia distributiva inextricablemente unida a ella. Más aún, una constitución establece cuál es el propósito final o dominante de una comunidad política. Se trata 
de una cuestión de naturaleza ética porque tiene que ver con la decisión de qué juzgan ser una vida buena la comunidad política y sus administradores y qué valores estiman importantes. En el libro IV de la Política, Aristóteles elabora una segunda definición más extensa de constitución que incluye dos aspectos éticos:

Una constitución es el orden de una polis de sus magistraturas, del modo de su distribución, quién ejerce el poder soberano y cuál es la finalidad de cada comunidad (Pol. IV, 1, 1289a15-18).

En el libro III, Aristóteles discute tanto las cuestiones éticas que presenta una justa distribución de los cargos políticos, como el verdadero propósito de una polis. Esto sugiere que elabora esa segunda definición para incluir los resultados que alcanzó en el libro III, y constituye también un argumento en favor de la unidad de la Política.

Después de rechazar la libertad y la riqueza como candidatos para constituirse como el verdadero propósito de una polis, Aristóteles menciona varios otros fines que no pueden ser los más elevados. Menciona como posibles la vida o la simple sobrevivencia, la defensa mutua frente al daño, el comercio y el beneficio mutuo y la mutua protección frente a la injusticia dañosa (Pol. III, 9, 1280a31-1280b5). Frente a estas posibilidades objeta que los tratados de comercio, los de defensa mutua y otras alianzas pueden darse entre naciones independientes y, por tanto, no constituyen una característica específica y propia de la polis. El fin de la protección mutua y de evitar el daño mutuo, o de relacionarse comercialmente, son solo

pre-condiciones que deben estar presentes antes de la existencia de la polis; pero la presencia de todas estas condiciones no basta para constituir una polis. Lo que

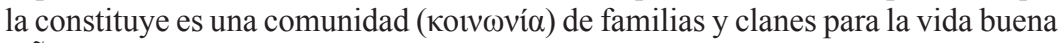
( $\varepsilon \tilde{\bigcup} \zeta \tilde{\eta} v)$, y con el fin de lograr una existencia perfecta y autosuficiente. [...] El fin $(\tau \dot{\varepsilon} \lambda \mathrm{\varsigma} \varsigma)$ de la polis es la vida buena, y esas cosas son un medio para ese fin. Y la polis es una comunidad de clanes y aldeas que existe de un modo perfecto y auto-suficiente, lo que en nuestra opinión constituye una vida feliz y noble ( $\tau$ ò $\zeta \tilde{\eta} v$

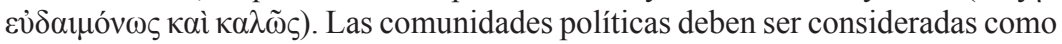

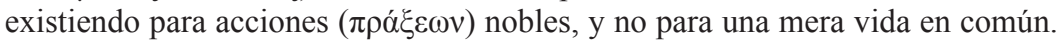
Por tanto, quienes contribuyen en una mayor medida a una comunidad tal deben tener una mayor participación que aquellos que son iguales o superiores a ellos en

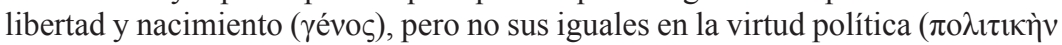

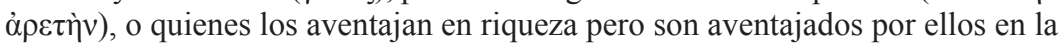
virtud (Pol. III, 91280b31-35,1280b39-1281a8).

El argumento para probar su preferencia política es parte de su teoría general de lo que constituye una distribución justa. Lo usual en una distribución de bienes es que haya diversas personas que manifiestan sus demandas y que ofrecen razones diferentes y encontradas para justificar esas demandas. Según la teoría de Aristóteles, la cuestión sobre qué razón tiene mayor justificación en el caso de una determinada distribución puede ser decidida si se considera el propósito de esa distribución. La razón justificativa no puede tener una conexión puramente fáctica con el propósito de la distribución sino que tiene que contribuir substantivamente a su logro. 
Una primera ilustración de esta teoría general puede verse en la crítica que elabora Aristóteles contra las concepciones oligárquica y democrática de la justicia distributiva (Pol. III, 9, 1280a22-31). Los partidarios de la oligarquía exigen mayor participación en los cargos y honores políticos por su mayor riqueza, lo que fundaría la justicia de sus demandas. Si el fin de la polis fuese la propiedad o la riqueza, los partidarios de la oligarquía tendrían en sus manos un poderoso argumento. Como ejemplo instructivo de las demandas encontradas de ricos y pobres, Aristóteles presenta una sociedad de dos individuos con un capital de 100 talentos. De estos 100 talentos, uno ha contribuido con 99 talentos y el otro con 1 talento. Es obvio que la persona que contribuyó con 1 talento podrá participar con una porción del capital total y recibirá un interés proporcional a su participación que será mucho menor que la del que aportó 99. Como la única finalidad de una compañía financiera es la maximización de la riqueza, ese interés extremadamente desigual se justifica. Pero para Aristóteles, la polis no es una empresa financiera y su finalidad no es la maximización de la riqueza o la propiedad. El pasaje no es claro, pero sugiere que su autor tenia en mente una crítica similar contra la concepción democrática de la justicia distributiva.

Una segunda ilustración de su teoría general es su ejemplo de la justa distribución de flautas. Si las flautas se distribuyen de manera justa, el que se distinga como un eximio flautista debería acceder a la mejor flauta ${ }^{14}$. Razones alternativas como una

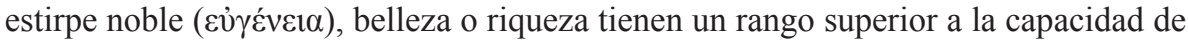
tocar flauta en la jerarquía de bienes. Pero esas razones no tienen una conexión fáctica con la finalidad de ser un eximio flautista, y no contribuyen nada para alcanzarla. Por esta razón se trata de criterios arbitrarios e irrelevantes para lograr una justa distribución de esos instrumentos musicales. Con este ejemplo, Aristóteles demuestra que los cargos y honores políticos no pueden asignarse según la superioridad en cualquier bien. Hay bienes, como el porte o la capacidad de correr rápido, que son irrelevantes en ese caso porque carecen de relevancia fáctica para el logro de la finalidad de la polis. Más aun, una distribución de acuerdo a la superioridad en cualquier bien presupondría que todos los bienes son comparables entre sí, lo cual resulta imposible dada la heterogeneidad e inconmensurabilidad de los bienes mencionados (Pol. III, 12, 1282b23-1283a11; cf. III, 4, 1277b29-30).

Aristóteles concede que los criterios de la libertad y la riqueza tienen algún peso en la distribución de cargos y honores. Una polis solo de esclavos no sería posible. Lo mismo sucedería con una solo de pobres. Tal polis no tendría ingresos impositivos y, como tal, carecería de medios para financiar asuntos públicos. Esto demuestra que tanto los ciudadanos ricos como los pobres, junto a sus cualidades, son contribuyentes indispensables para la existencia de la polis. Pueden, por tanto, exigir su debida participación en los asuntos políticos. Sin embargo, para Aristóteles la virtud política es la que debe considerarse el criterio de valor más justificado para determinar la distribución de cargos y honores. 
El primer paso en su argumentación en favor de la concepción aristocrática de la justicia distributiva es la tesis fundamental de que el propósito específico de la polis es una vida buena y feliz, por oposición a la mera supervivencia, la riqueza, la libertad u otra finalidad. La gente está de acuerdo en que las flautas deben distribuirse para tocar bien, pero no hay consenso acerca de cuál sería el verdadero propósito de la polis. Como segundo paso, Aristóteles afirma su teoría general de la justicia distributiva, según la cual una demanda justificada de distribución no solo debe estar fácticamente conectada con el propósito de la distribución, sino que debe también contribuir sustantivamente a su realización. El paso final es mostrar que la virtud política contribuye en mayor grado a la realización de una vida buena y feliz que la libertad, la riqueza o un nacimiento noble. En conclusión, puede afirmarse que una concepción aristocrática de la justicia distributiva tiene razones más justificadas que las otras tres concepciones, lo que demuestra que Aristóteles la prefiere claramente.

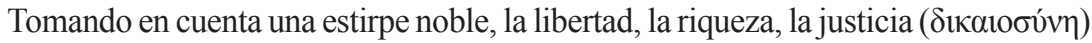

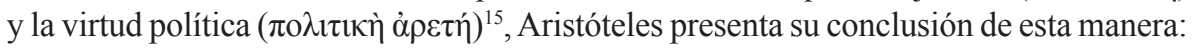

Podría parecer, por cierto, que todas o al menos algunas de estas afirmaciones son con razón discutibles en lo que concierne a la existencia de una polis, pero todavía lo son muchísimo más en lo que se refiere a la vida buena, la educación y la virtud, como ya lo hemos dicho ${ }^{16}$ (Pol. III, 13, 1283a23-26).

Al igual que Platón, Aristóteles sostiene que la "educación ( $\left.\pi \alpha \_\delta \varepsilon i ́ \alpha\right)$ " y la "virtud" son los criterios apropiados de valor en la justa distribución de cargos y honores políticos (Leyes VI, 757c). Tanto la educación como la virtud no deben considerarse como reivindicaciones que compitan entre sí. La educación debe entenderse más bien como la formación del alma que conduce a la virtud ética, a un carácter virtuoso. Para Aristóteles, al igual que para Teognis, la virtud ética más importante es la justicia como un atributo del carácter o disposición ( $\left.\varepsilon_{\xi} \xi \zeta\right)$. Desde una edad temprana, la educación debe informar la conducta y también los hábitos con la finalidad de producir un carácter virtuoso. Para Aristóteles, la educación debería no solo enfatizar la justicia subjetiva sino también otras virtudes éticas como la valentía y la moderación ( $\sigma \omega \varphi \rho o \sigma u ́ v \eta)$

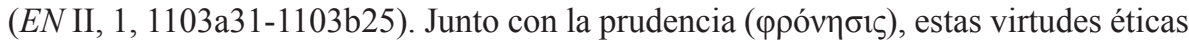

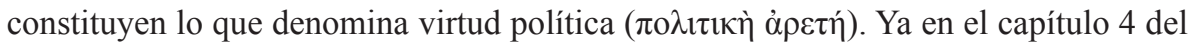
libro tercero, menciona la prudencia como una virtud característica del buen gobernante

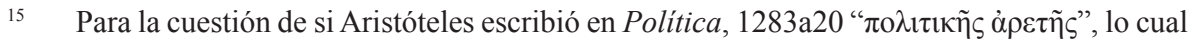

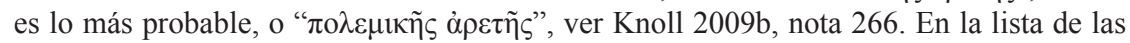

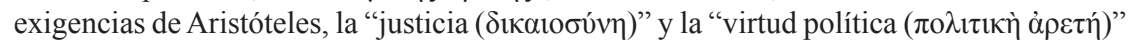
no deben entenderse como exigencias rivales ya que para él la justicia es parte de la virtud política. Cf. Pol. III, 9, 1281a7-8.

16 Esta afirmación se refiere a la versión breve del argumento de Aristóteles en Pol. III, 9, $1280 \mathrm{~b} 39-1281 \mathrm{a} 8$. 
(1277a14-15; cf. Elm 1996). La virtud política es la razón más justificada en el caso de la distribución de cargos y honores ${ }^{17}$.

No es muy difícil ver como la virtud política contribuye sustancialmente a la tarea de alcanzar la vida buena, que es la finalidad de la polis. El practicar la virtud política como ciudadano es lo mismo que actuar bien y vivir políticamente. En su vida política activa, un ciudadano lleva a cabo acciones virtuosas a favor de su polis tanto en la asamblea como en el consejo, los tribunales y la actividad bélica. Para Aristóteles, una vida política activa, en la que los ciudadanos deliberen, gobiernen y construyan la polis, equivale a una vida buena y feliz. Una vida tal busca el honor, y como un fin todavía más alto, la virtud (EN I, 3, 1095b22-31). De la virtud política de los ciudadanos depende si la polis prospera o perece, si puede mantener una existencia autosuficiente o no, y si una constitución es estable o debe enfrentar la sedición y la guerra civil. Si los ciudadanos políticamente virtuosos conservan la estabilidad del orden político y aseguran que la polis sea autosuficiente y floreciente habrán afianzado la libertad y la riqueza, que constituyen importantes medios para una vida buena y feliz. Al igual que la paz y el ocio, la estabilidad y la prosperidad son las mejores condiciones de una fructífera vida contemplativa, la vida buena del científico o del filósofo. Si una vida política virtuosa es capaz de alcanzar estas metas, contribuirá a la realización de una forma de vida, que como Aristóteles argumenta en la Ética a Nicómaco, es aún más feliz que la vida política (EN X,7-9,1177a12-1179a32).

Según la clasificación que elabora Aristóteles de las convicciones políticas de la época, para los demócratas lo que tiene valor es "la libertad, para los partidarios de la oligarquía la riqueza, para otros resulta ser una noble estirpe, y para los aristócratas es la virtud" ( $E N \mathrm{~V}, 6,1131$ a27-29). Esta sección ha demostrado que para Aristóteles el criterio apropiado de valor es la virtud política. Es también la razón que justifica una determinada distribución de cargos y honores políticos. Por tanto, de acuerdo con esta clasificación, debe ser considerado como partidario de una concepción aristocrática de la justicia distributiva ${ }^{18}$. Más aún, esta sección ha hecho evidente que para Aristóteles

17 Para una interpretación similar de la evaluación aristotélica del papel que juega la virtud política, ver Gordon 2007, 145, 154, y Schütrumpf 1980, 146. Según Ada Neschke-Hentschke, para Aristóteles la virtud política se compone de prudencia (der praktischen Klugheit) y un ethos justo (dem gerechten Ethos) (Neschke-Hentschke 2012, 115).

18 Cf. Miller 1995, 127. David Keyt distingue entre una concepción aristocrática y una concepción aristotélica de la justicia distributiva. Esta última tiene un criterio valorativo que incluye no solo la virtud, sino también la riqueza y la libertad (Keyt 1991, 247, 259). El criterio aristotélico incluye, sin duda, riqueza y libertad, pero eso ocurre también en el caso del criterio aristocrático. Por tanto, no es necesario introducir concepción de justicia distributiva aristotélica adicional. La interpretación de Keyt es incoherente en su propio artículo, ya que, a continuación, afirma correctamente que la mejor polis de Aristóteles es una "verdadera aristocracia" que encarna "la concepción aristotélica de la justicia distributiva" (Keyt 1991, 260). Como cada constitución expresa su correspondiente concepción, es razonable entender que la contenida en la aristocracia es también una concepción aristocrática de la justicia distributiva. 
toda constitución contiene o encarna una concepción de la justicia distributiva. En consecuencia, debe ser considerado, en cuanto a sus convicciones políticas, como un partidario de la aristocracia.

\section{La aristocracia como la constitución de la mejor polis}

Antes de definir la constitución de la mejor polis, Aristóteles establece cuál es el modo de vida más apetecido. Las características específicas de la mejor polis, de la ciudad, de acuerdo a nuestros deseos ( $\left.\kappa \alpha \tau^{\prime} \varepsilon \chi_{\chi} \chi \eta^{\prime} v\right)$, es que los ciudadanos puedan vivir en ella la mejor vida y la más feliz (Pol. VII, 4, 1325b36). Para lograr este fin, deben desarrollar virtudes humanas específicas y llegar a ser perfectamente buenos y virtuosos, lo que exige una excelente disposición natural, una educación de primera, y condiciones sociales como riqueza, ocio y el no estar atados al trabajo. Dado que estas demandas son muy exigentes, hay que suponer que la mejor polis tiene pocos ciudadanos.

La estructura social de la mejor polis aristotélica está configurada como una pirámide. Su cúspide está formada por una pequeña clase de individuos virtuosos y que gozan de ocio. Los estratos inferiores corresponden a la vasta mayoría de individuos que habitan la polis como no-ciudadanos. Esos individuos son los extranjeros, los inmigrantes, y también los esclavos y los bárbaros que carecen de ciudadanía y corresponden a los jornaleros, marineros, campesinos, comerciantes y artesanos. Aristóteles cree que los miembros de la clase trabajadora no participan en la polis, y son solo las condiciones y medios indispensables para ella (Pol. VII, 9, 1329a34-39). Justifica la exclusión de la clase trabajadora por la finalidad de la polis. Para vivir una vida buena y feliz se necesita la virtud. Pero la clase trabajadora carece de la disposición natural, la educación y las condiciones sociales necesarias para su cultivo (Pol. VII, 9, 1329a21-24). La clase trabajadora debe servir a la clase que dispone del ocio como un instrumento para el logro de una vida buena y feliz. También anota que quienes pertenecen a esa clase tienen un valor menor y han sido formados por la naturaleza para servir instrumentalmente a quienes pertenecen a un rango superior en el orden natural (cf. Knoll 2009b, 200-01).

Según la segunda definición que da Aristóteles, una constitución “es el orden de una polis relacionado con sus varios cargos y su distribución, con su poder soberano y con el fin ( $\tau \varepsilon \dot{\lambda} \lambda \circ \varsigma)$ de la comunidad" (Pol. IV, 1, 1289a15-18). El fin de la mejor polis es indudablemente la vida buena y feliz, lo que requiere que los ciudadanos desarrollen y practiquen sus virtudes éticas e intelectuales en un contexto de vida política y teórica. Esta es una importante razón por la que la constitución de la mejor polis no puede ser considerada como una politeia. Aristóteles afirma más de una vez que los ciudadanos de una politeia, el promedio de los hombres en Grecia, están lejos de ser virtuosos en plenitud (Pol. III, 7, 1279a39-1279b4; IV, 11, 1295a25-31). No poseen, en consecuencia, las cualidades requeridas de los ciudadanos en la mejor polis (cf. Schütrumpf 1980, 159). La mejor polis aspira a la vida buena y feliz, y por tanto a la virtud. Esto explica que en los libros VII y VIII de la Política Aristóteles dedique mucha atención a la educación. 
Aristóteles no detalla las instituciones políticas concretas de la mejor polis. Para determinar su constitución es necesario analizar su pensamiento con respecto a cómo se distribuyen las funciones y el poder político. Todos los ciudadanos de la mejor polis son buenos, virtuosos y justos. Son todos iguales entre sí. Es por ello que todos tienen el derecho a participar en el gobierno de la polis. Aristóteles señala que "por muchas razones es necesario que todos participen por igual en la capacidad de gobernar y de ser gobernados. La igualdad significa trato igual a iguales personas, y constitución que no se funde en la justicia puede escasamente sobrevivir" (Pol. VII, 14, 1332b25-29). De acuerdo a la concepción de la justicia distributiva que encarne la constitución de la mejor ciudad, todos los ciudadanos deben participar en el gobierno porque todos son igualmente buenos y virtuosos. Igual participación es necesaria no solo por razones de justicia, sino por motivos que tienen que ver con la preservación de la polis. En conexión con su análisis del cambio de constituciones, en el libro V Aristóteles argumenta que una constitución injusta es frecuentemente inestable porque conduce a la sedición.

Cuando Aristóteles afirma que "es necesario que todos participen en el gobierno y en el ser a su vez gobernados" podría ser malentendido en el sentido de que la mejor constitución sería una politeia o una democracia ${ }^{19}$. Un análisis de lo que Aristóteles quiere decir por 'participación' excluye esta interpretación. A continuación del pasaje citado, explica que no está en discusión que los que gobiernan tengan que ser mejores que sus súbditos. En referencia a lo sostenido en parágrafos anteriores, sostiene que la naturaleza ha distinguido entre personas del mismo tipo, determinando que unos sean más jóvenes y otros más viejos. Lo más apropiado para los ciudadanos jóvenes es ser gobernados y para los viejos gobernar. Esto no debería ofender a los jóvenes porque su turno llegaría con los años (Pol. VII, 14, 1332b35-42).

Aristóteles relaciona esos dos grupos con dos diferentes cualidades y dos tareas políticas distintas. El grupo de los ancianos tiene la tarea política de deliberar, juzgar en los tribunales y gobernar la polis. Lo jóvenes deben proteger al gobierno de quienes no quieran obedecer y no defiendan a la polis de ataques externos. Con respecto a las cualidades de los dos grupos, Aristóteles declara que por naturaleza los ciudadanos

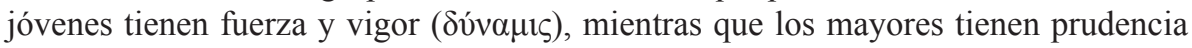
( $\varphi \rho o ́ v \eta \sigma ı)$. La constitución de la mejor polis confía ambas tareas a las mismas personas, pero no en la misma etapa de sus vidas. Ahora bien, al asignar ambas tareas a todos y cada uno de los ciudadanos asegura la igual participación de todos en la vida política. Aristóteles justifica de este modo esta distribución de las tareas políticas siguiendo la concepción aristocrática de la justicia:

19 Éste es un malentendido fundamental en la interpretación que da Nussbaum de la explicación de la participación política sostenida por Aristóteles. Nussbaum pretende que para Aristóteles "la mejor ciudad es una politeia" $(2001,147)$, y que entiende la participación como una forma democrática de participación (Nussbaum 1990a; cf. 2000, 109). Erróneamente, intenta fundar esta tesis en la afirmación de Aristóteles citada arriba (Pol. VII, 14, 1332b25-27; cf. Knoll 2009b, 260-63). 
Por naturaleza, la fuerza se encuentra en los jóvenes y la prudencia en los viejos; esta distribución parece conveniente y justa; esta distinción corresponde también a una consideración de valor (Pol. VII, 9, 1329a14-17).

En la mejor polis, los cargos políticos y el poder supremo se distribuyen de acuerdo al valor. En su constitución, el criterio apropiado de valor es primariamente la prudencia, la virtud intelectual que, combinada con las virtudes éticas, es constitutiva de la virtud política $^{20}$. Esto demuestra que la constitución de la mejor polis expresa una concepción aristocrática de la justicia distributiva (cf. Keyt 1991, 260). Debido a que, según Aristóteles, cada constitución encarna un correspondiente tipo de justicia distributiva, la constitución de la mejor polis debe entenderse como la aristocrática. La cita de más arriba indica que la constitución de la mejor polis no puede ser una politeia. Aristóteles define la politeia como una mezcla de democracia y oligarquía (Pol. IV, 8/9, 1294a15-b17). De forma análoga, la concepción de la justicia distributiva de la politeia es una mezcla de los criterios de libertad y riqueza. La cita anterior demuestra que esos criterios tienen poca relevancia para una distribución justa de cargos políticos.

Aristóteles describe la constitución de la mejor polis como una aristocracia. Pero considera el caso de un ciudadano que se distinga como poseedor de tan extraordinaria virtud que sobrepase en exceso a todos los otros ciudadanos (Pol. VII, 14, 1332b1627). De acuerdo con su teoría de la justicia, a tal individuo excelso debería asignársele el poder supremo, haciéndolo rey. Sin embargo, tales individuos raramente existen y la consideración de Aristóteles es más hipotética que práctica. Dado que la virtud es el criterio axiológico tanto de la aristocracia cuanto de la monarquía, y la aristocracia y la monarquía son constituciones emparentadas, él las considera subespecies de la mejor constitución (Pol. IV, 2, 1289a30-33).

El argumento que la constitución de la mejor polis encarna una concepción aristocrática de la justicia distributiva no es la única razón que fundamenta la tesis de que se trata de una aristocracia. Corresponde también a las características de lo que Aristóteles concibe como una "verdadera aristocracia". En el libro IV, se refiere a su consideración de la aristocracia en el libro III y habla de una "verdadera aristocracia" como la "primera y mejor constitución" (Pol. IV, 7, 1293b1-3,19; cf. IV, 2, 1289a3033). Define la "verdadera aristocracia" como una "constitución fundada en individuos que son absolutamente los mejores según su virtud, y no en hombres buenos solo en relación a otro criterio" (Pol. IV, 7, 1293b3-5). Solo en una "verdadera aristocracia" los "individuos buenos son absolutamente los mismos que los buenos ciudadanos; en todas las otras constituciones el buen ciudadano es solo bueno en relación con su propia forma de constitución" (Pol. IV, 7, 1293b5-7). En todas las otras constituciones, aparte de la "verdadera aristocracia," los ciudadanos no se distinguen por poseer una "absolutamente justos" (Pol. VII, 9, 1328b38). 
virtud perfecta, o la virtud del hombre perfecto. La virtud del ciudadano se orienta por su constitución particular. Como hay muchas formas de constitución, "es evidente que no hay una sola virtud que sea la virtud perfecta. Pero cuando hablamos de un hombre bueno queremos señalar que este posee una única virtud que es la virtud perfecta" (Pol. III, 4, 1276b31-34). Los ciudadanos de la mejor polis son todos perfectamente buenos y virtuosos y la constitución se funda en tales hombres. Tan pronto como ellos alcancen la edad en la que pueden ser considerados prudentes, "la virtud del ciudadano y del gobernante coinciden con la del hombre bueno". Aristóteles indica que la "virtud del hombre bueno y la del buen ciudadano son idénticas en la mejor polis". Como la constitución de la mejor polis está fundada en los hombres mejores y más virtuosos, corresponde exactamente con lo que caracteriza a la "verdadera aristocracia"(Pol. VII, 14, 1333a11-12; III, 18, 1288a38-39; VII ,9, 1328b38-39).

La tesis de que la constitución de la mejor polis es una verdadera aristocracia puede fundarse en un tercer argumento relacionado con el segundo. La finalidad de la mejor polis es una vida buena y feliz. Esto presupone un énfasis en la educación para cultivar las virtudes necesarias para ese fin. Una verdadera aristocracia tiene la misma finalidad y los mismos requisitos para cultivar la virtud. En el contexto de la distinción entre tres tipos de aristocracia, en el libro IV Aristóteles deja establecido que las aristocracias se preocupan de la virtud y prestan atención pública a su cultivo (Pol. IV, 7, 1293b12-13; cf. Pol. IV, 2, 1289a30-33).

Como se indicó supra, hay dos corrientes opuestas de interpretación con respecto a lo que constituye la convicción política fundamental de Aristóteles. Un análisis de las interpretaciones equivocadas, que sostienen que su mejor polis es una politeia, muestra que sus representantes descuidan su distinción entre las cuatro tareas de la teoría constitucional que articula al comienzo del libro IV de la Política. La más importante de estas distinciones es aquella entre la tarea de "estudiar cuál es la mejor constitución", y la tarea de "determinar la forma constitucional más adecuada a todos los estados" (Pol. IV, 1, 1288b21-24, 33-35; cf. Knoll 2011a,136-140). En tanto Aristóteles realiza su estudio de la mejor constitución en los libros VII y VIII, examina la politeia principalmente en los libros IV-VI. La politeia es lo más adecuado para todos los estados, porque la mayoría de ellos, en los tiempos de Aristóteles, eran democracias u oligarquías, y la politeia es una combinación estable de los elementos de esas dos constituciones inestables (Pol. IV, 8/9, 1294a15-b 17).

Si tomamos en serio la afirmación de Aristóteles de que la misma ciencia tiene cuatro tareas distintas, muchos malentendidos y supuestas contradicciones de la Política desaparecerían junto con la necesidad de postular diferentes estratos en su origen. Mientras que en los libros IV-VI, que son de corte empírico, Aristóteles se involucra científicamente en las realidades políticas de su tiempo y asume el papel de consejero político realista, en los libros VII y VIII, basados en su concepción de la justicia distributiva y de la perfección humana, revela sus preferencias políticas normativas. 
Este trabajo ha intentado demostrar que esas preferencias son aristocráticas y que Aristóteles pertenece a la tradición aristocrática de pensamiento político ${ }^{21}$.

\section{Referencias bibliográficas}

Appel, Fredrick (1999), Nietzsche contra Democracy. Ithaca/London. Aristóteles (1954), Ethica Nicomachea. I. Bywater, Oxonii. (1957), Politica. W.D. Ross, Oxonii.

Barker, Ernest (1959), The Political Thought of Plato and Aristotle. New York.

Bates, Clifford Angell, Jr. (2003), Aristotle's “Best Regime”. Baton Rouge.

Bien, Günther (1980), Die Grundlegung der politischen Philosophie bei Aristoteles. Freiburg/München.

Brobjer, Thomas H. (1995), Nietzsche's Ethics of Character. Uppsala.

Cristi, Renato (2014), "Nietzsche, Theognis and Aristocratic Radicalism", en Manuel Knoll/Barry Stocker (eds.), Nietzsche as Political Philosopher. Berlin/Boston, 173-194.

Chuska, Jeff (2000), Aristotle's Best Regime. Lanham/Cumnor Hill.

Depew, David J. (1991), "Politics, Music, and Contemplation in Aristotle's Ideal State, en David Keyt/Fred D. Miller, Jr. (eds.), A Companion to Aristotle's "Politics". Cambridge/Oxford, 346-380.

Detwiler, Bruce (1990), Nietzsche and the Politics of Aristocratic Radicalism. Chicago/London.

Elm, Ralf (1996), Klugheit und Erfahrung bei Aristoteles. Paderborn.

Gordon, John-Stewart (2007). Aristoteles über Gerechtigkeit. Freiburg/München.

Keyt, David/Fred D. Miller, Jr. (eds.) (1991), A Companion to Aristotle's "Politics". Cambridge/Oxford.

Keyt, David (1991), “Aristotle's Theory of Distributive Justice”, en David Keyt/Fred D. Miller (eds.), A Companion to Aristotle's "Politics". Cambridge/Oxford, 238-278.

21 En este ensayo estudio a Aristóteles desde un punto de vista normativo, es decir, tomo en cuenta su ideal moral del perfeccionamiento humano. Dejo de lado la atención que Aristóteles presta a la realidad política de su época y su intención de ofrecer consejo político. En este sentido, observo que el libro IV, 9 de la Política considera un balance o mediación entre ricos y pobres y recomienda el fortalecimiento de la clase media. Michael Sandel observa que la preocupación de Aristóteles con respecto a la desigualdad social es una de las fuentes intelectuales de la tradición republicana, pues ésta advierte "que una desigualdad severa socava la libertad pues corrompe el carácter moral de ricos y pobres, y destruye el sentido comunitario que requiere el autogobierno"(Sandel 1996, 330). 
Knoll, Manuel (2009a), "Nietzsches Begriff der sozialen Gerechtigkeit", Nietzsche Studien, Vol. 38, 2009, 156-181.

(2009b), Aristokratische oder demokratische Gerechtigkeit? Die politische Philosophie des Aristoteles und Martha Nussbaums egalitaristische Rezeption. München/Paderborn.

(2011a), "Die Politik des Aristoteles - eine unitarische Interpretation", Zeitschrift für Politik (ZfP), 2, 123-147.

(2011b), "Die Politik des Aristoteles - Aufsatzsammlung oder einheitliches Werk? Replik auf Eckart Schütrumpfs Erwiderung”, Zeitschrift für Politik, 4, 410-423.

Middleton, Christopher (editor/trad) (1996). Selected Letters of Friedrich Nietzsche. Indianapolis.

Miller, Fred D. (1991), "Aristotle on Natural Law and Justice”, en David Keyt/Fred D. Miller, (eds.): A Companion to Aristotle's "Politics". Cambridge/Oxford, 279-306.

(1995), Nature, Justice, and Rights in Aristotle's "Politics". Oxford.

Mulgan, Richard (1991), "Aristotle's Analysis of Oligarchy and Democracy", en David Keyt/Fred D. Miller (eds.), A Companion to Aristotle's "Politics". Cambridge/Oxford, 307-322.

Neschke-Henschke, Ada (2012), "Recht und Gerechtigkeit”, en Barbara Zehnpfennig (ed.), Die "Politik" des Aristoteles (Staatsverständnisse), Baden Baden, 106125.

Newman, William Lambert (1887-1902), The Politics of Aristotle. Vol. II, Oxford.

Nietzsche, Friedrich (2015), On Theognis of Megara, Renato Cristi/Oscar Velásquez (eds.). Cardiff.

Nussbaum, Martha (1990a), “Aristotelian Social Democracy”, en R. Bruce Douglass/ Gerald M. Mara/Henry S. Richardson (eds.), Liberalism and the Good. New York/London, 203-252.

(1990b), "Nature, Function, and Capability: Aristotle on Political Distribution", en Günther Patzig (ed.), 'Aristoteles ' "Politik”, 152-186.

(2000), "Aristotle, Politics, and Human Capabilities: A Response to Antony, Arneson, Charlesworth, and Mulgan", Ethics, Vol. 111, 1, 102-140.

(2001), "Love, Literature, and Human Universals: Comments on the Papers", en Angela Kallhoff (ed.), Martha C. Nussbaum: Ethics and Political Philosophy. Münster, 129-152.

Ottmann, Henning (2001), Geschichte des politischen Denkens. Die Griechen. Bd. $1 / 2$, Stuttgart.

Polansky, Ronald (1991), “Aristotle's on Political Change", en David Keyt/Fred D. Miller (eds.), A Companion to Aristotle's "Politics". Cambridge/Oxford, 322345. 
Rowe, Christopher (1991), "Aims and Methods in Aristotle's Politica", en David Keyt/Fred D. Miller (eds.), A Companion to Aristotle's "Politics”. Cambridge/ Oxford, 57-74.

Sandel, Michael (1996), Democracy's Discontent: America's Search for a Public Philosophy. Cambridge: Mass.

Schöpsdau, Klaus (1994), Platon. Nomoi (Gesetze). Buch I-III, Übersetzung und Kommentar, Göttingen.

Schütrumpf, Eckart (1980), Die Analyse der Polis durch Aristoteles. Amsterdam.

Sternberger, Dolf (1984), Drei Wurzeln der Politik. Frankfurt am Main. 